\title{
Reactions of triene-conjugated diazo-compounds containing thiophene
}

\author{
John T. Sharp*, Alastair G. Cessford, and Alister R. Stewart ${ }^{1}$ \\ Department of Chemistry, University of Edinburgh, West Mains Road, Edinburgh, \\ EH10 6RW, Scotland \\ E-mail: j.t.sharp@ed.ac.uk
}

Dedicated to Professor Charles Rees on the occasion of his $75^{\text {th }}$ birthday

(received 30 May 02; accepted 28 Jul 02; published on the web 05 Aug 02)

\begin{abstract}
Triene-conjugated diazo-compounds 12a,b which have a thiophene ring as the $\alpha, \beta$ double bond and olefinic groups at the $\gamma, \delta$ and $\varepsilon, \zeta$ positions react via intramolecular $(3+2)$ cycloaddition to the $\varepsilon, \zeta$ bond to give the methano-bridged thieno[2,3- $d$ ]diazocines 21a,b in high yield. This is wholly different reaction path to that followed by their analogues $\mathbf{6 / 1 1}$ that have a benzene ring at the $\alpha, \beta$ position. The latter react via an intramolecular 1,1 -cycloaddition process followed by rearrangment to give the pyrrolo[2,1-a]phthalazines 8.
\end{abstract}

Keywords: Diazo-compound, conjugated 1,3-dipolar intermediate, (3+2) cycloaddition

\section{Introduction}

Recent work ${ }^{2}$ on the chemistry of triene-conjugated diazo-compounds of the general type $\mathbf{1}$ has shown that they can react via a variety of routes, and that the preferred reaction path depends strongly on both the nature of the substituents attached to the pendant diene system, and the stereochemistry about the $\gamma, \delta$ double bond.

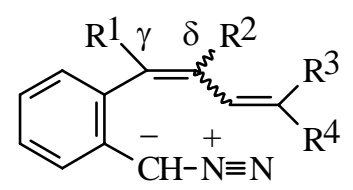

1

Systems in which the triene system includes a cyclopentene ring at the $\gamma, \delta$ position, e.g. 2 (Scheme 1), react rapidly at room temperature by an intramolecular $(3+2)$ cycloaddition reaction 
to give the bridged benzodiazocine systems 3 (70-80\%), accompanied in some cases by the hydrocarbon 4 in low yield. The occurrence of this cycloaddition reaction seems to be uniquely dependent on the presence of the 5-membered ring. Its inclusion apparently results in a highly favourable stereochemical disposition of the two reacting groups as illustrated in structure $\mathbf{5}$, which leads to the dominance of this reaction path. In the absence of the cyclopentene ring, e.g. in the $\gamma, \delta$-cis systems 6 (Scheme 2), the diazo-compounds are much longer-lived and react on heating by an entirely different path leading predominantly to the carbene-derived hydrocarbons 7 (ca. 75\%) and the phthalazines 8 (ca. 25\%). The latter are thought to be formed via a 1,1cycloaddition to the $\gamma, \delta$ bond to give $\mathbf{9}$ followed by ring cleavage and ring expansion as shown. In a similar reaction of $\mathbf{1 1}$, the trans analogues of $\mathbf{6}$, the phthalazines $\mathbf{8}$ are formed as the exclusive products in $c a .75 \%$ yield. $^{3}$

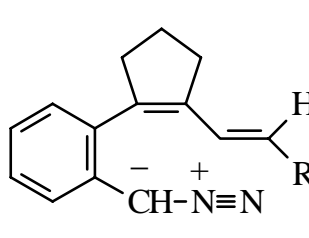

2<smiles>[R4]C1[C@H]2N=N[C@H]1c1ccccc1C1=C2CCC1</smiles>

3<smiles>[R4]C1C2C3=C(CCC3)c3ccccc3C12</smiles>

4<smiles>[R1]C1CCCC2=C1CCC2=CC</smiles>

5

\section{Scheme 1}

1,1-Cycloaddition reactions are relatively rare in diazo-compound chemistry ${ }^{4 \mathrm{a}-\mathrm{c}}$ and this reaction provided the first example in conjugated systems of this type. It was therefore of interest to study its possible extension to the related systems $\mathbf{1 2 / 1 3}$ in which the benzene ring is replaced by thiophene, which, if they should react in the same way, would lead to the formation of $\mathbf{1 4}$.

\section{Results}

The diazo-compounds studied were the cis and trans isomers 12a,b and 13a,b. They were generated, as in earlier work ${ }^{2}$, by the thermal decomposition of the sodium salts of the corresponding tosylhydrazones 18 and 20 under aprotic conditions in 1,2-dimethoxyethane (DME) as solvent. 


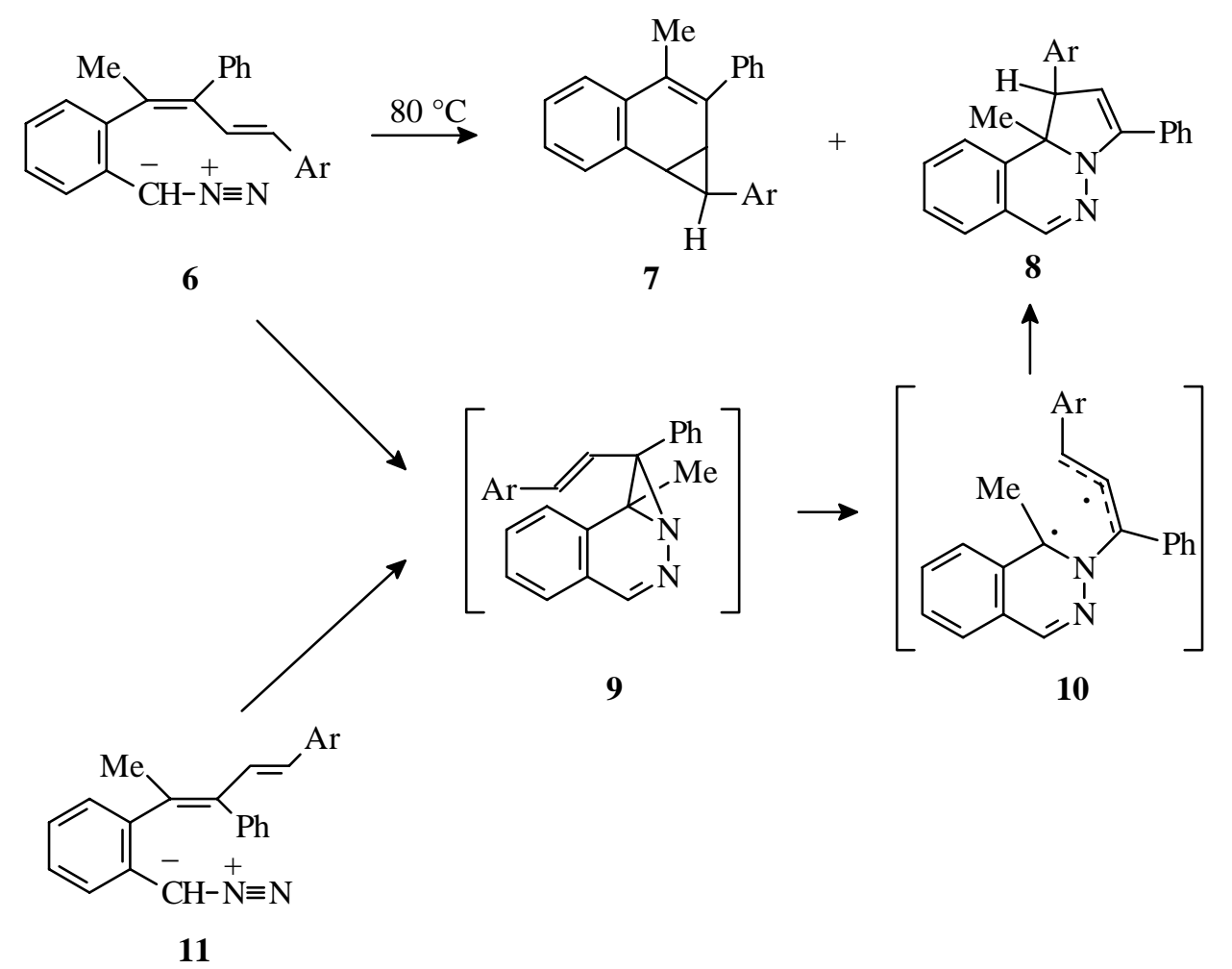

\section{Scheme 2}

The synthesis of the tosylhydrazones is illustrated for the $\gamma, \delta$ cis isomers 18a,b in Scheme 3.The aldehydes 17 were prepared by Suzuki coupling reactions of 2-formylthiophene-3-boronic acid with the appropriate bromodiene 16. The bromodienes were prepared by Wittig or Wadsworth-Emmons olefination reactions of (Z)-3-bromo-2-phenylbut-2-enal 15. The latter and its $(E)$ isomer were prepared as a mixture from benzyl methyl ketone via Arnold's bromoformylation reaction $^{5 \mathrm{a}, \mathrm{b}}$ and were separated by chromatography. The $\gamma, \delta$ trans isomers 19a,b were prepared by a parallel route. The tosylhydrazones were all single isomers except for 19a $(\mathrm{Ar}=\mathrm{Ph})$ which was obtained as a mixture of $E / Z$ isomers at the terminal double bond which could not be separated.

The $\gamma, \delta$ cis diazo-compound 12a $(\mathrm{Ar}=\mathrm{Ph})$ was first generated by heating its precursor tosylhydrazone salt at reflux in DME (ca. $\left.80^{\circ} \mathrm{C}\right)$ and gave two products, the methano-bridged thienodiazocine 21a (38\%), and the cyclopropabenzothiophene 22 (56\%) as shown in Scheme 4. They were identified by comparison of their mass and NMR spectra with the corresponding benzo analogues 3 and $\mathbf{4}$. For example, the ${ }^{1} \mathrm{H}$ NMR spectrum of 21a showed three singlets at $\delta$ 3.56, 5.38, and 5.70 for the methine protons at the 1,9 , and 12 positions which corresponded to the absorptions at 3.28, 5.26, and 5.71 for the equivalent protons in $3\left(\mathrm{R}^{4}=\mathrm{Ph}\right)$. The lack of spin coupling between $\mathrm{H}-12$ and its adjacent protons, due to their nearly orthogonal orientation, was 
also observed in 3 . The reaction was then repeated under milder conditions - room temperature for 2 days followed by heating at $50{ }^{\circ} \mathrm{C}$ for 4 hours.<smiles></smiles>

12a,b<smiles>C/C(=C(\C=[14CH])c1ccsc1[CH]C#N)c1ccsc1</smiles>

$13 \mathbf{a}, \mathbf{b}$<smiles>[Z11]C1C=C(c2ccccc2)C([M])C1c1cccs1</smiles>

14 (a, $\left.\mathrm{Ar}_{\mathrm{r}}=\mathrm{Ph} ; \mathrm{b}, \mathrm{Ar}_{\mathrm{r}}=\mathrm{C}_{6} \mathrm{~F}_{5}\right)$<smiles>CC(Br)=C(C=O)c1ccccc1</smiles>

15<smiles>CCC=CC(=C(C)C)c1ccccc1</smiles>

16<smiles></smiles>

17

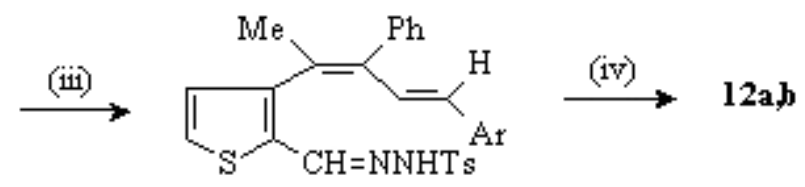

18

Scheme 3. Reagents: i, $\mathrm{ArCH}_{2} \mathrm{P}^{+} \mathrm{Ph}_{3} \mathrm{X}^{-}$or $\mathrm{ArCH}_{2} \mathrm{P}(\mathrm{O})(\mathrm{OEt})_{2} /$ base; ii, 2-formylthiophene-3boronic acid / $\mathrm{Pd}\left(\mathrm{PPh}_{3}\right)_{4} / \mathrm{NaHCO}_{3}$; iii, TsNHNH${ }_{2} / \mathrm{H}^{+}$, iv, Na salt in DME

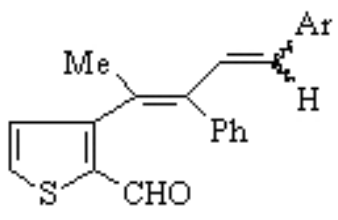

19ab<smiles>CCC=CC(=Cc1cccs1)C(C)=Cc1ccccc1</smiles>

20ab

In this case the only product was the diazocine 21a, isolated in $70 \%$ yield. This suggests that, at the higher reaction temperature, 22 was formed primarily by extrusion of nitrogen from 21a. This reaction path was confirmed by heating an NMR sample of 21a. However, it is possible that 22 was also formed directly via 23, the carbene generated by the loss of nitrogen from 12a. The second example of this type of reactant, $\mathbf{1 2 b}\left(\mathrm{Ar}=\mathrm{C}_{6} \mathrm{~F}_{5}\right)$, under the milder reaction conditions, reacted in the same way to give the thienodiazocine $\mathbf{2 1 b}\left(\mathrm{Ar}=\mathrm{C}_{6} \mathrm{~F}_{5}\right)(63 \%)$. This product also showed the three characteristic ${ }^{1} \mathrm{H}$ NMR absorptions at $\delta 4.00,5.34$, and 5.85.

The $\gamma, \delta$ trans diazo-compound 13a $(\mathrm{Ar}=\mathrm{Ph})$, generated by heating its precursor tosylhydrazone salt at reflux in DME, failed to react via any intramolecular reaction path and gave as the major product the 'carbene dimer' 25 (54\%) and the azine 24 (40\%), both presumably 
formed, as shown in Scheme 5, by reaction of the carbene 23a $\left(\mathrm{Ar}=\mathrm{C}_{6} \mathrm{H}_{5}\right)$ with its diazocompound precursor.

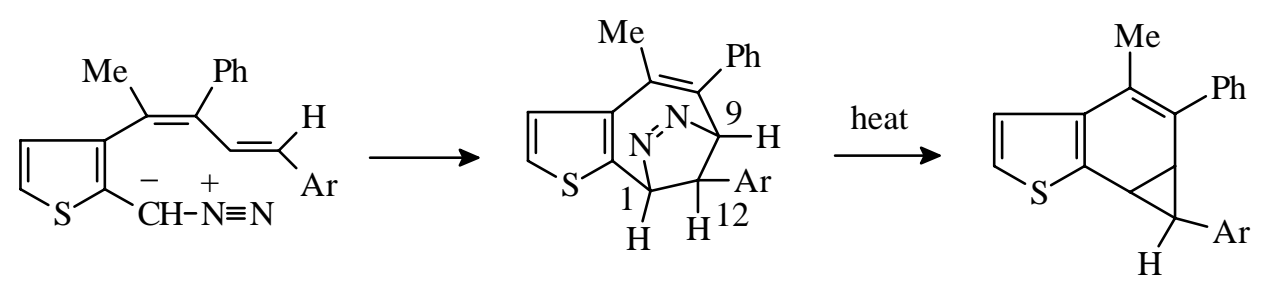

12a,b

21a/b
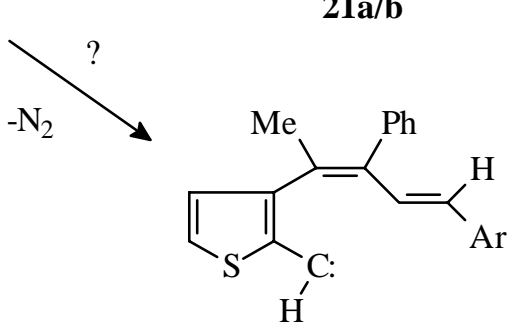

22

\section{Scheme 4}

The azine had the expected spectroscopic properties and its identity was confirmed by comparison with a sample prepared directly by reaction of the corresponding aldehyde with hydrazine. The 'carbene dimer' 25 had a mass spectrum consistent with its proposed structure with a parent $(\mathrm{M}+1)^{+}$ion at $\mathrm{m} / \mathrm{z} 629$ and a major fragment at $\mathrm{m} / \mathrm{z} 314$. However further characterisation was impossible as the compound could not be obtained in a pure state due to further reaction or polymerisation which gave products with very similar TLC retention characteristics.

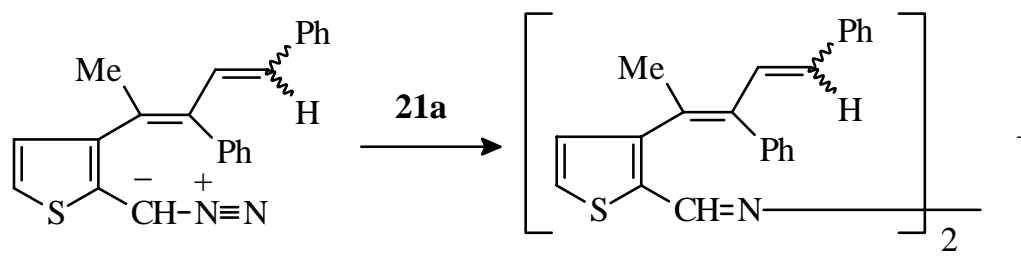

13a

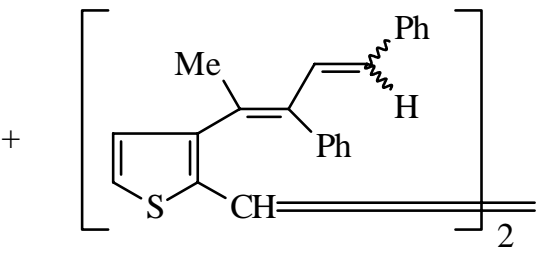

25

\section{Scheme 5}

A similar reaction was carried out under higher dilution and milder conditions (room temperature for 7 days) in an effort to favour an intramolecular reaction path. This gave only a complex mixture of products. The other trans reactant $\mathbf{1 3 b}\left(\mathrm{Ar}=\mathrm{C}_{6} \mathrm{~F}_{5}\right)$ also gave a complex mixture of products that were not separated or identified. However, the primary product mixture 
and several components separated by chromatography were examined by ${ }^{1} \mathrm{H}$ NMR spectroscopy and it was clear that a product of the type $\mathbf{1 4}$, analogous to $\mathbf{8}$, had not been formed.

\section{Discussion}

These results show that the replacement of the benzene ring in the $\alpha, \beta$ position of $\mathbf{6}$ (and 11) with a thiophene ring resulted in a complete change in the preferred reaction path. Whereas the former gave the phthalazines 8 via a 1,1-cycloaddition reaction with the $\gamma, \delta$ bond and the subsequent rearrangement shown in Scheme 2, the latter completely failed to follow that reaction path. Instead the cis isomers 12a,b reacted predominantly to give 21a,b (Scheme 4) via a path analogous to that taken by the cyclopentene containing species 2 (Scheme 1). The trans isomers 13a,b reacted only via intermolecular paths (Scheme 5). Their failure to react via a 1,1 cycloaddition process (Scheme 6) leading to $\mathbf{1 4}$ is even more notable since this was the dominant high-yielding path for their benzo analogues 11 (Scheme 2).

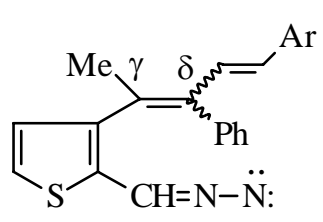

12/13a,b

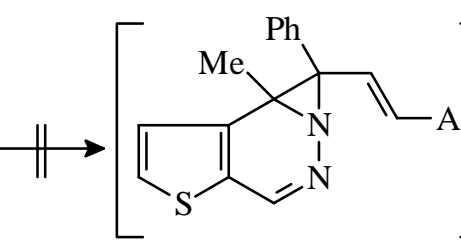

26

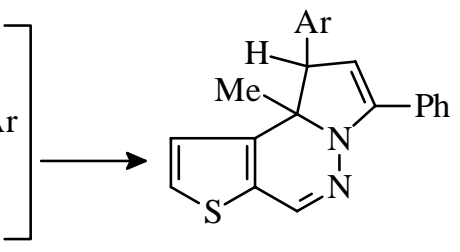

14

\section{Scheme 6}

It seems likely that these results stem from the effect of the thiophene ring in compounds 12/13a,b on their molecular geometry. Firstly, the exocyclic bond angles at the $\alpha$ and $\beta$ positions in these compounds will be greater than in the benzene analogues 6/11 (72 $c f .60^{\circ}$, assuming symmetrical rings) resulting in an increase in the distance separating the terminal $\mathrm{N}$ atom of the diazo-group from the $\gamma, \delta$ bond. This would increase the activation energy for the 1,1cycloadition process for both 12 and $\mathbf{1 3}$ and make these processes less competitive with the many other reactions paths possible for these systems.

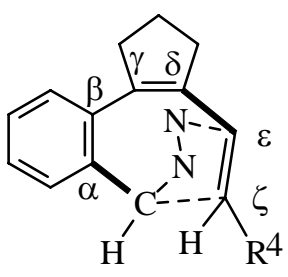

27

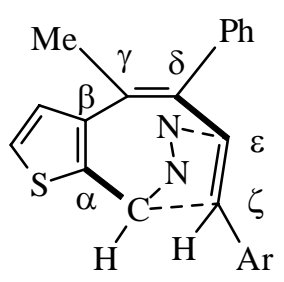

28 
Secondly, for the cis isomers, it would appear that the transition state for the intramolecular $(3+2)$ reaction, 28, is strongly favoured by the presence of the thiophene ring, in the same way that the benzene analogue, 27, is favoured by the presence of the cyclopentene ring. The sum of the included bond angles is much the same in each case leading to a similar spatial disposition of the reacting groups.

The 1,1-cycloaddition shown in Scheme 2 thus remains the only example yet observed in the reactions of diene- or triene-conjugated diazo-compounds ${ }^{2}$ and these results highlight the fine balance between competing reaction paths in these systems.

\section{Experimental Section}

General Procedures. All ${ }^{1} \mathrm{H}$ and ${ }^{19} \mathrm{~F}$ NMR spectra were run at $250 \mathrm{MHz}$ and all ${ }^{13} \mathrm{C}$ NMR spectra at $62.9 \mathrm{MHz}$ using $\mathrm{CDCl}_{3}$ as solvent unless otherwise stated. TMS was used as the internal standard for all ${ }^{1} \mathrm{H}$ and ${ }^{13} \mathrm{C}$ spectra. $\mathrm{CFCl}_{3}$ was used as the external standard for all ${ }^{19} \mathrm{~F}$ spectra. Chemical shifts are quoted in parts per million (ppm) and $J$ values are given in $\mathrm{Hz} .{ }^{1} \mathrm{H}$ and ${ }^{19} \mathrm{~F}$ NMR signals are described as singlets (s), doublets (d), triplets (t), quartets (q), multiplets (m) or broad (br) or a combination of these. In the ${ }^{13} \mathrm{C}$ spectra, carbon multiplicity was established by single frequency off-resonance decoupling or by distortionless enhancement by polarisation transfer (DEPT). Mass spectra were obtained using electron ionisation at $70 \mathrm{eV}$ unless otherwise stated. IR spectra were recorded as films or Nujol mulls. Preparative chromatography ${ }^{6}$ was carried out on silica gel by the flash column method (Merck Kieselgel 60, 230-400 mesh), the 'dry-column flash' method ( $15 \mu \mathrm{m}$, Fluka Kieselgel G) or the 'medium pressure' (MPLC) technique using 100 x 2.5 cm columns (Merck Kieselgel 60, 230-400 mesh), and eluting solvents based on hexane admixed with ether. Ether refers to diethyl ether. All drying of solutions was done with anhydrous magnesium sulfate. Tetrahydrofuran (THF) and 1,2dimethoxyethane (DME) were distilled from calcium hydride as required. Chloroform was passed through a column of activated alumina and stored over $4 \AA$ molecular sieves.

2-Formyl-3-thiopheneboronic acid was used as supplied by the Aldrich Chemical Company. $(E)$ and (Z)-3-Bromo-2-phenylbut-2-enal ${ }^{5 b}$ 15, 4-bromo-1,3-diphenylpenta-1,3-diene ${ }^{5 b} 16$ $(\mathrm{Ar}=\mathrm{Ph})$ as a mixture of $(Z, Z)$ and $(E, Z)$ isomers, $(E, E)-4$-bromo-1,3-diphenylpenta-1,3diene $^{5 b}$, and diethyl $\left(2,3,4,5,6\right.$-pentafluorobenzyl)phosphonate ${ }^{7}$ were prepared by known routes.

(E,Z)-4-Bromo-1-perfluorophenyl-3-phenylpenta-1,3-diene. A solution of diethyl (2,3,4,5,6pentafluorobenzyl)phosphonate $(0.68 \mathrm{~g}, 2.0 \mathrm{mmol})$ in dry THF $\left(40 \mathrm{~cm}^{3}\right)$ was cooled to $0{ }^{\circ} \mathrm{C}$ under dry nitrogen and $n$-butyllithium $\left(0.8 \mathrm{~cm}^{3}, 2.5 \mathrm{M}\right.$ in hexane, $\left.2.0 \mathrm{mmol}\right)$ was added dropwise. This solution was stirred at $0{ }^{\circ} \mathrm{C}$ for 2 hours, upon which (E)-3-bromo-2-phenylbut-2enal $(0.40 \mathrm{~g}, 1.8 \mathrm{mmol})$ in dry THF $\left(5 \mathrm{~cm}^{3}\right)$ was added. The reaction was stirred at room temperature for 2 hours, then quenched with ammonium chloride solution $\left(40 \mathrm{~cm}^{3}, 25 \% \mathrm{w} / \mathrm{v}\right)$. 
The aqueous phase was extracted with ether $\left(2 \mathrm{x} 25 \mathrm{~cm}^{3}\right)$ and the combined organic layers were washed with water $\left(25 \mathrm{~cm}^{3}\right)$, dried and the solvents were removed in vacuo. Flash column chromatography (silica, 9:1 hexane-ether) gave (E,Z)-4-bromo-1-perfluorophenyl-3phenylpenta-1,3-diene as a low-melting white solid (0.35 g, $0.90 \mathrm{mmol}, 45 \%$ ), (Found $\mathrm{M}^{+}$, 387.9887 and $\mathrm{M}^{+}$, 389.9868. $\mathrm{C}_{17} \mathrm{H}_{10}{ }^{79} \mathrm{BrF}_{5}$ requires $\mathrm{M}^{+}$, 387.9886. $\mathrm{C}_{17} \mathrm{H}_{10}{ }^{81} \mathrm{BrF}_{5}$ requires $\mathrm{M}^{+}$, 389.9867); $\delta_{\mathrm{H}}(200 \mathrm{MHz}) 2.69\left(3 \mathrm{H}, \mathrm{s}, \mathrm{CH}_{3}\right), 5.88(1 \mathrm{H}, \mathrm{d}, J$ 16.2, olefinic H-4), 7.11-7.16 (2 H, m, 2 x Ar-H), 7.16-7.47 (3 H, m, 3 x Ar-H), 7.58 (1 H, d, J 16.2, H-1); $\delta_{\mathrm{C}} 25.37\left(\mathrm{CH}_{3}\right), 112.38$ (quat, C-(CF) $\left.)_{5}\right), 116.81$ (CH, C-2), 127.61 (CH, Ar), 128.05 (quat), 128.39 (2 x CH, Ar), 129.30 ( $2 \times \mathrm{CH}, \mathrm{Ar}$ ), 135.59 (CH, $\mathrm{CH}-\mathrm{C}_{6} \mathrm{~F}_{5}$ ), 139.46 (quat), 140.18 (quat), 5 x quat C-F unobserved; $\delta_{\mathrm{F}}$ (235 MHz, $\mathrm{CDCl}_{3}$ ) -163.26 to -163.50 (2 F, m, Ar-F), -156.55 (1 F, t, J 20.6, para-F), -142.86 to -143.00 (2 F, m, Ar-F). A repeat reaction gave the product in a yield of $69 \%$.

(E,E)-4-Bromo-1-perfluorophenyl-3-phenylpenta-1,3-diene. To an ice-cooled solution of diethyl (2,3,4,5,6-pentafluorobenzyl)phosphonate $(1.56 \mathrm{~g}, 4.9 \mathrm{mmol})$ in dry THF $\left(30 \mathrm{~cm}^{3}\right)$ was added $n$-butyllithium $\left(2.0 \mathrm{~cm}^{3}, 2.5 \mathrm{M}\right.$ in hexane, $\left.5.0 \mathrm{mmol}\right)$. This solution was stirred at $0{ }^{\circ} \mathrm{C}$ for an hour, then warmed to room temperature. A solution of (Z)-3-bromo-2-phenylbutenal (1.0 g, $4.44 \mathrm{mmol})$ in THF $\left(10 \mathrm{~cm}^{3}\right)$ was added and the solution was stirred for 2 hours. Saturated ammonium chloride solution $\left(30 \mathrm{~cm}^{3}\right)$ was added and the organic layer was separated. The aqueous phase was extracted with ether $\left(2 \times 30 \mathrm{~cm}^{3}\right)$ and the combined organic extracts were washed with water $\left(20 \mathrm{~cm}^{3}\right)$, dried and the solvents were removed in vacuo. Flash column chromatography (silica, hexane) gave (E,E)-4-bromo-1-perfluorophenyl-3-phenylpenta-1,3-diene as a colourless oil which solidified on cooling (1.03 g, $2.7 \mathrm{mmol}, 61 \%$ ), mp $85-87^{\circ} \mathrm{C}$ (hexane), (Found $\mathrm{M}^{+}$, 387.9891 and $\mathrm{M}^{+}$, 389.9866. $\mathrm{C}_{17} \mathrm{H}_{10}{ }^{79} \mathrm{BrF}_{5}$ requires $\mathrm{M}^{+}$, 387.9886 $\mathrm{C}_{17} \mathrm{H}_{10}{ }^{81} \mathrm{BrF}_{5}$ requires $\mathrm{M}^{+}$, 389.9867); $\delta_{\mathrm{H}}(200 \mathrm{MHz}) 2.26\left(3 \mathrm{H}, \mathrm{s}, \mathrm{CH}_{3}\right), 5.86(1 \mathrm{H}, \mathrm{d}, J 16.2$, olefinic $\mathrm{H}-4)$, 7.11-7.25 (2 H, m, Ar-H), 7.34-7.48 (3 H, m, Ar-H), $7.86\left(1 \mathrm{H}, \mathrm{d}, J\right.$ 16.2, H-1); $\delta_{\mathrm{C}} 27.47\left(\mathrm{CH}_{3}\right)$, 112.38 (quat C-CF), 117.83 (CH, C-2 ), 127.03 (quat, C-Me), 127.84 (CH, Ar-H), 128.67 (2 x CH, Ar-H), 129.38 (2 x CH, Ar-H), 136.69 (quat), 138.45 (CH, t, J JCF 8.0, CH-C $\mathrm{F}_{5}$ ), 138.90 (quat), 5 x quat C-F unobserved; $\delta_{\mathrm{F}}(235.4 \mathrm{MHz})-142.68$ to -142.82 (m, 2 x F), -156.67 (1 F, t, $J$ 20.8), -163.41 to -163.64 (m, $2 \times \mathrm{F})$.

2-Formyl-3-(1-methyl-2,4-diphenylbuta-1,3-dienyl)thiophene 17a $(\mathrm{Ar}=\mathrm{Ph})$ as a 5:1 mixture of $(\boldsymbol{E}, \boldsymbol{E})$ and $(\boldsymbol{E}, \boldsymbol{Z})$ isomers. A mixture of $(E, E)$-4-bromo-1,3-diphenylpenta-1,3-diene (1.17 g, $3.9 \mathrm{mmol}$ ) and tetrakis-(triphenylphosphine)palladium(0) (135 mg, $0.117 \mathrm{mmol}, 3 \mathrm{~mol} \%$ catalyst $)$ in DME $\left(20 \mathrm{~cm}^{3}\right)$ was stirred for $1 \mathrm{~h}$ at room temperature. Sodium bicarbonate $(0.98 \mathrm{~g}$, $11.7 \mathrm{mmol})$ and 2-formyl-3-thiopheneboronic acid $(0.60 \mathrm{~g}, 3.9 \mathrm{mmol})$ in water $\left(10 \mathrm{~cm}^{3}\right)$ were added and the mixture heated at reflux for $1.5 \mathrm{~h}$, cooled to room temperature and stirred for an additional $24 \mathrm{~h}$. The solvent was removed in vacuo and water $\left(30 \mathrm{~cm}^{3}\right)$ added. This mixture was extracted with DCM $\left(3 \times 50 \mathrm{~cm}^{3}\right)$ and the combined organic layers were washed with water $\left(60 \mathrm{~cm}^{3}\right)$, dried and evaporated in vacuo to give a yellow oil. Flash column chromatography (silica, hexane $\rightarrow 25 \%$ ether/hexane) followed by crystallisation gave a 5:1 mixture of $(E, E)$ - and (E,Z)-2-formyl-3-(1-methyl-2,4-diphenylbuta-1,3-dienyl)thiophene (0.76 g, 56\%) which could not be separated, mp $103-105{ }^{\circ} \mathrm{C}$ (hexane-ethanol), (Found $\mathrm{M}^{+}$, 330.1076. $\mathrm{C}_{22} \mathrm{H}_{18} \mathrm{OS}$ requires 


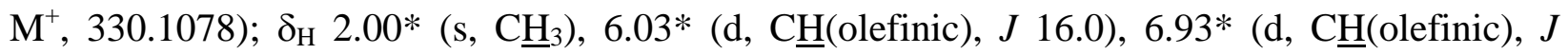

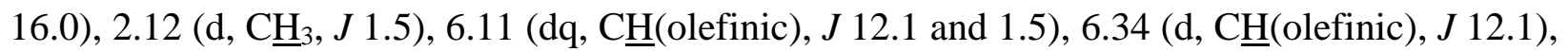
6.67 ( $1 \mathrm{H}, \mathrm{d}, \underline{\mathrm{H}}_{4}, J$ 5.0), 7.04-7.56 (12 H, m, thiophene $\mathrm{C} \underline{H}^{\prime}$ s and $\left.\mathrm{Ph}\right), 7.84^{*}\left(1 \mathrm{H}, \mathrm{dd}, \underline{\mathrm{H}}_{5}, J 5.0\right.$

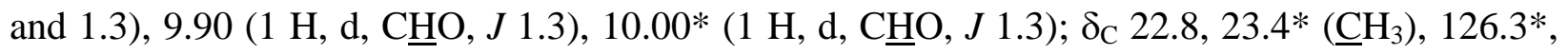
126.7, 127.2, 127.2*, 127.4, 127.5*, 127.9, 128.1, 128.3*, 128.4*, 129.2, 129.5*, 130.0*, 130.1, 131.7, 133.1*, 133.2, 134.5* (ㄷH olefinic and aromatic), 136.5, 136.9*, 138.6, 137.8*, 138.7*, 139.4, 141.9*, 152.5*, 152.6*, 154.0, 155.5, 159.5 (quaternary olefinic and aromatic), 183.4, $183.5^{*}$ ( $\mathrm{CHO}$ ) (* indicates the major isomer).

(E,E)-2-Formyl-3-(1-methyl-2,4-diphenylbuta-1,3-dienyl)thiophene $p$-tosylhydrazone (18a, $\mathbf{A r}=\mathbf{P h})$. A solution of $p$-tosylhydrazide $(0.35 \mathrm{~g}, 1.6 \mathrm{mmol})$ in ethanol $\left(10 \mathrm{~cm}^{3}\right)$ was added to a solution of $(E, E)$ - and (E,Z)-2-formyl-3-(1-methyl-2,4-diphenylbuta-1,3-dienyl)thiophene (0.59 $\mathrm{g}, 1.8 \mathrm{mmol})$ in ethanol $\left(10 \mathrm{~cm}^{3}\right)$. The reaction mixture was heated at $40{ }^{\circ} \mathrm{C}$ for $1 \mathrm{~h}$, cooled to room temperature and stirred overnight. The solvent was removed in vacuo to give a yellow foam. Crystallisation gave (E,E)-2-formyl-3-(1-methyl-2,4-diphenylbuta-1,3-dienyl)thiophene $p$ tosylhydrazone (0.641 g, 72\%) as pale yellow crystals, mp $149-151{ }^{\circ} \mathrm{C}$ (hexane-ethanol), (Found $(\mathrm{M}+1)^{+}$, 499.1507. $\mathrm{C}_{29} \mathrm{H}_{26} \mathrm{~N}_{2} \mathrm{O}_{2} \mathrm{~S}_{2}$ requires $(\mathrm{M}+1)^{+}$, 499.1514); $\delta_{\mathrm{H}}\left(\left[\mathrm{D}_{6}\right]-\mathrm{DMSO}\right) 1.75(3 \mathrm{H}, \mathrm{s}$,

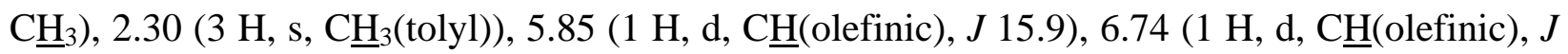

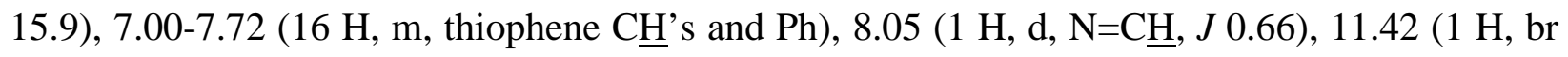

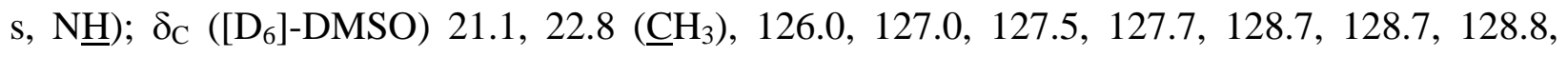
129.0, 129.1, 129.6, 129.7, 131.5, 143.5 (ㄷH olefinic and aromatic), 131.3, 133.5, 136.2, 136.9, 138.8, 139.7, 141.5, 144.8 (quaternary olefinic and aromatic).

(E,E)-2-Formyl-3-(4-perfluorophenyl-1-methyl-2-phenylbuta-1,3-dienyl)thiophene (17b, Ar $\left.=\mathbf{C}_{6} \mathbf{F}_{5}\right)$. A mixture of (E,E)-4-bromo-1-perfluorophenyl-3-phenylpenta-1,3-diene (1.55 g, $4.0 \mathrm{mmol}$ ) and tetrakis-(triphenylphosphine)palladium(0) (138 mg, $0.120 \mathrm{mmol}, 3 \mathrm{~mol} \%$ catalyst) in DME $\left(20 \mathrm{~cm}^{3}\right)$ was stirred for $1 \mathrm{~h}$ at room temperature. Sodium bicarbonate $(1.00 \mathrm{~g}$, $12.0 \mathrm{mmol})$ and 2-formyl-3-thiopheneboronic acid $(0.65 \mathrm{~g}, 4.0 \mathrm{mmol})$ in water $\left(20 \mathrm{~cm}^{3}\right)$ were added and the mixture heated at reflux for $3.5 \mathrm{~h}$, cooled to room temperature and stirred for an additional $24 \mathrm{~h}$. The solvent was removed in vacuo and water $\left(30 \mathrm{~cm}^{3}\right)$ added. This mixture was extracted with DCM (3 x $\left.60 \mathrm{~cm}^{3}\right)$ and the combined organic layers washed with water $\left(60 \mathrm{~cm}^{3}\right)$, dried and evaporated in vacuo to give a dark brown oil. Flash column chromatography (silica, hexane $\rightarrow 25 \%$ ether/hexane) followed by crystallisation gave (E,E)-2-formyl-3-(4perfluorophenyl-1-methyl-2-phenylbuta-1,3-dienyl)thiophene (1.20 g, 72\%) as pale yellow crystals, mp 80-82 ${ }^{\circ} \mathrm{C}$ (hexane), (Found $\mathrm{M}^{+}$, 420.0609. $\mathrm{C}_{22} \mathrm{H}_{13} \mathrm{~F}_{5} \mathrm{OS}$ requires $\mathrm{M}^{+}$, 420.0607); $\delta_{\mathrm{H}}$ 2.05 (3H, s, $\underline{\mathrm{C}}_{3}$ ), 5.91 (1 H, d, $\mathrm{C} \underline{\mathrm{H}}$ (olefinic), J 16.3), 7.17-7.88 (8 H, m, thiophene $\underline{\mathrm{H}}^{\prime}$, $\mathrm{Ph}$ and

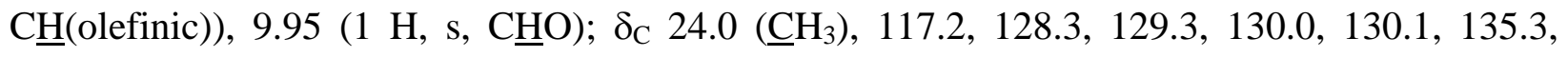
137.2, (ㅡㅐ olefinic and aromatic), 112.8, 134.1, 136.0, 137.3, 137.8, 142.3, 142.8, 146.7, 152.0 (quaternary olefinic, aromatic and $\underline{\mathrm{C}}-\mathrm{F}), 183.5$ (ㄷHO).

(E,E)-2-Formyl-3-(4-perfluorophenyl-1-methyl-2-phenylbuta-1,3-dienyl)thiophene p-tosylhydrazone (18b, $\left.\mathbf{A r}=\mathbf{C}_{6} \mathbf{F}_{5}\right)$. A solution of $p$-tosylhydrazide $(0.27 \mathrm{~g}, 1.6 \mathrm{mmol})$ in ethanol $\left(10 \mathrm{~cm}^{3}\right)$ was added to a solution of (E,E)-2-formyl-3-(4-perfluorophenyl-1-methyl-2- 
phenylbuta-1,3-dienyl)thiophene $(0.51 \mathrm{~g}, 1.2 \mathrm{mmol})$ in ethanol $\left(10 \mathrm{~cm}^{3}\right)$. The reaction mixture was heated at $40{ }^{\circ} \mathrm{C}$ for $1 \mathrm{~h}$, cooled to room temperature and stirred overnight. The solvent was removed in vacuo to give a pale yellow oil. Flash column chromatography (silica, 70\% ether/hexane) followed by crystallisation gave (E,E)-2-formyl-3-(4-perfluorophenyl-1-methyl-2phenylbuta-1,3-dienyl)thiophene $p$-tosylhydrazone $(0.576 \mathrm{~g}, 82 \%)$ as white crystals, mp 150$151{ }^{\circ} \mathrm{C}$ (hexane-ethanol), (Found $(\mathrm{M}+1)^{+}$, 589.1062. $\mathrm{C}_{29} \mathrm{H}_{21} \mathrm{~F}_{5} \mathrm{~N}_{2} \mathrm{O}_{2} \mathrm{~S}_{2}$ requires $(\mathrm{M}+1)^{+}$, 589.1043); $\delta_{\mathrm{H}}\left(\left[\mathrm{D}_{6}\right]-\mathrm{DMSO}\right) 2.03\left(3 \mathrm{H}, \mathrm{s}, \mathrm{C}_{3}\right), 2.54\left(3 \mathrm{H}, \mathrm{s}, \mathrm{C}_{3}(\mathrm{tolyl})\right), 5.90(1 \mathrm{H}, \mathrm{d}$, C $\underline{H}$ (olefinic), $J$ 16.4), 7.24 (1 H, d, C $\underline{H}$ (olefinic), $J 16.4$ ), 7.34 (1 H, d, $\underline{H}_{4}, J$ 5.15), 7.50-7.95 (10 $\mathrm{H}, \mathrm{m}, \mathrm{Ph}$ and $\left.\underline{\mathrm{H}}_{5}\right), 8.23$ (1 H, d, N=C,$J$ 0.62), 11.69 (1 H, br s, $\underline{\mathrm{H}}$ ); $\delta_{\mathrm{C}}\left(\left[\mathrm{D}_{6}\right]-\mathrm{DMSO}\right) 21.7$, $23.7\left(\mathrm{CH}_{3}\right), 115.5,127.8,128.7,129.6,129.8,130.4,138.2,141.8$ ( $\underline{\mathrm{CH}}$ olefinic and aromatic), 112.8, 129.6, 134.7, 136.0, 136.5, 137.0, 140.5, 142.6, 144.2, 144.7, 146.5 (quaternary olefinic, aromatic and $\underline{\mathrm{C}}-\mathrm{F}) ; \delta_{\mathrm{F}}(235.4 \mathrm{MHz})\left(\left[\mathrm{D}_{6}\right]-\mathrm{DMSO}\right)-16.7$ (1F, t, $p$-CE, $J$ 22.2), -22.2 (2F, td, $m$ CE, $J 7.3$ and 23.1), -155.3 (2F, dd, $o-C \underline{F}, J 7.3$ and 23.2).

2-Formyl-3-(1-methyl-2,4-diphenylbuta-1,3-dienyl)thiophene (19a, $\mathrm{Ar}=\mathrm{Ph})$ as a 6:1 mixture of $(Z, Z)$ and $(Z, E)$ isomers. A mixture of $(Z, Z)$ - and (E,Z)-4-bromo-1,3-diphenylpenta1,3-diene ( $0.77 \mathrm{~g}, 2.6 \mathrm{mmol}$ ) and tetrakis(triphenylphosphine)palladium(0) $(90 \mathrm{mg}, 0.078 \mathrm{mmol}$, $3 \mathrm{~mol} \%$ catalyst $)$ in DME $\left(10 \mathrm{~cm}^{3}\right)$ was stirred for $1 \mathrm{~h}$ at room temperature. Sodium bicarbonate (0.65 g, $7.8 \mathrm{mmol})$ and 2-formyl-3-thiopheneboronic acid $(0.40 \mathrm{~g}, 2.6 \mathrm{mmol})$ in water $\left(10 \mathrm{~cm}^{3}\right)$ were added and the mixture heated at reflux for $1.5 \mathrm{~h}$, cooled to room temperature and mixed for an additional hour. The solvent was removed in vacuo and water $\left(20 \mathrm{~cm}^{3}\right)$ added. This mixture was extracted with DCM $\left(3 \times 40 \mathrm{~cm}^{3}\right)$ and the combined organic layers washed with water $\left(50 \mathrm{~cm}^{3}\right)$, dried and evaporated in vacuo to give a yellow oil which solidified on standing. Flash column chromatography (silica, $50 \%$ ether/hexane) followed by crystallisation gave a 6:1 mixture of (Z,Z)- and (Z,E)-2-formyl-3-(1-methyl-2,4-diphenylbuta-1,3-dienyl)thiophene (0.66 g, $78 \%$ ) which could not be separated, mp 132-134 ${ }^{\circ} \mathrm{C}$ (hexane-ethanol), (Found $\mathrm{M}^{+}$, 330.1074. $\mathrm{C}_{22} \mathrm{H}_{18} \mathrm{OS}$ requires $\mathrm{M}^{+}, 330.1078$ ); $\delta_{\mathrm{H}} 1.93 *\left(\mathrm{~s}, \mathrm{C}_{3}\right.$ ), 6.32* (d, $\mathrm{C} \underline{\mathrm{H}}$ (olefinic), $J$ 12.1), 6.62* (d, C (olefinic), J 12.1), 2.34 (s, $\underline{\mathrm{C}}_{3}$ ), 6.19 (d, $\underline{\mathrm{CH}}$ (olefinic), $J$ 16.0), 6.77-7.48 (13 H, m, thiophene

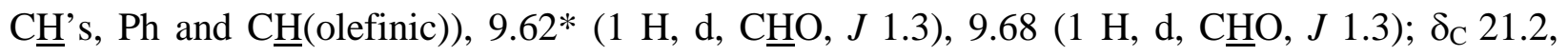
23.3* $\left(\mathrm{CH}_{3}\right), 126.5,126.7^{*}, 127.3^{*}, 127.9^{*}, 128.1^{*}, 128.5,129.3^{*}, 129.6^{*}, 130.1^{*}, 130.2$, 132.1*, 133.6, 133.8*, 134.1 (ㄷH olefinic and aromatic), 128.4*, 136.9, 137.1, 137.2*, 137.4, 137.5*, 138.7*, 138.9, 139.2*, 141.0, 152.9*, 153.8 (quaternary olefinic and aromatic), 183.1*, 183.1 ( $\mathrm{CHO})$ (* indicates the major isomer).

2-Formyl-3-(1-methyl-2,4-diphenylbuta-1,3-dienyl)thiophene $p$-tosylhydrazone (20a, $\mathrm{Ar}=$ Ph) as a 2:1 mixture of $(Z, Z)$ and $(Z, E)$ isomers. A solution of $p$-tosylhydrazide $(0.30 \mathrm{~g}$, $1.6 \mathrm{mmol})$ in ethanol $\left(10 \mathrm{~cm}^{3}\right)$ was added to a solution of $(Z, Z)$ - and $(Z, E)-2$-formyl-3-(1-methyl2,4-diphenylbuta-1,3-dienyl)thiophene $(0.49 \mathrm{~g}, 1.5 \mathrm{mmol})$ in ethanol $\left(10 \mathrm{~cm}^{3}\right)$. The reaction mixture was heated at $40{ }^{\circ} \mathrm{C}$ for $1 \mathrm{~h}$, cooled to room temperature and stirred overnight. The solvent was removed in vacuo to give a yellow-brown oil which solidified on standing. Crystallisation gave a 2:1 mixture of (Z,Z)- and (Z,E)-2-formyl-3-(1-methyl-2,4-diphenylbuta1,3-dienyl)thiophene $p$-tosylhydrazone $(0.650 \mathrm{~g}, 87 \%)$ which could not be separated, mp 124- 
$126{ }^{\circ} \mathrm{C}$ (ethanol), (Found $(\mathrm{M}+1)^{+}$, 499.1521. $\mathrm{C}_{29} \mathrm{H}_{26} \mathrm{~N}_{2} \mathrm{O}_{2} \mathrm{~S}_{2}$ requires $\left.(\mathrm{M}+1)^{+}, 499.1514\right) ; \delta_{\mathrm{H}}$ ([D $\left.\left.\mathrm{D}_{6}\right]-\mathrm{DMSO}\right) 1.80^{*}$ (d, $\underline{\mathrm{C}}_{3}, J$ 1.2), 2.38* (s, $\mathrm{C}_{3}$ (tolyl)), 6.37* (dd, C (olefinic), $J 12.2$ and

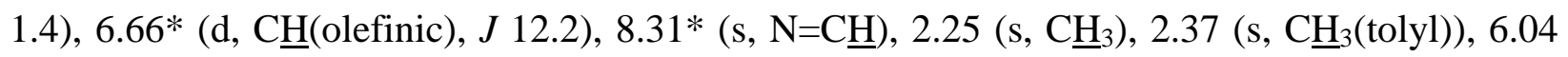

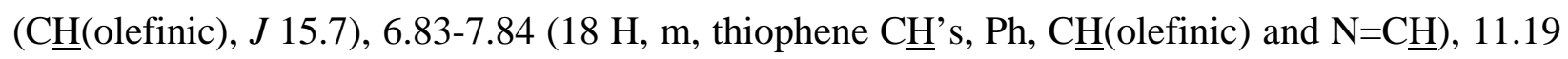

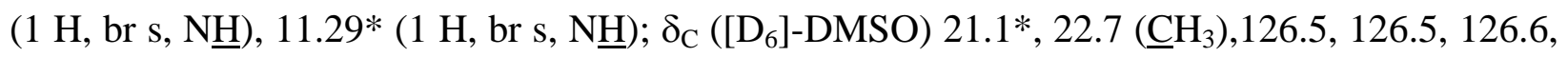
$127.1^{*}, 127.4,127.5^{*}, 127.6,127.7^{*}, 127.8,128.0,128.2 *, 128.3^{*}, 128.8,129.2^{*}, 129.3,129.4$, $129.5^{*}, 129.7^{*}, 130.0^{*}, 131.4^{*}, 132.4,141.2^{*}, 141.6$ (CEH olefinic and aromatic), 129.1*, 131.5, 132.2*, 135.3, 136.2, 137.0*, 137.1*, 137.7, 139.2, 139.4, 139.7*, 141.6, 142.9*, 143.4*, 145.3*, 146.8 (quaternary olefinic and aromatic) (* indicates the major isomer).

(Z,E)-2-Formyl-3-(4-perfluorophenyl-1-methyl-2-phenylbuta-1,3-dienyl)thiophene (19b, Ar $\left.=\mathbf{C}_{6} \mathbf{F}_{5}\right)$. A mixture of (E,Z)-4-bromo-1-perfluorophenyl-3-phenylpenta-1,3-diene (1.00 g, $2.4 \mathrm{mmol}$ ) and tetrakis-(triphenylphosphine)palladium(0) (85 mg, $0.072 \mathrm{mmol}, 3 \mathrm{~mol} \%$ catalyst) in DME $\left(10 \mathrm{~cm}^{3}\right)$ was stirred for $1 \mathrm{~h}$ at room temperature. Sodium bicarbonate $(0.60 \mathrm{~g}$, $7.2 \mathrm{mmol})$ and 2-formyl-3-thiopheneboronic acid $(0.37 \mathrm{~g}, 3.9 \mathrm{mmol})$ in water $\left(10 \mathrm{~cm}^{3}\right)$ were added and the mixture heated at reflux for 2 h, cooled to room temperature and mixed for an additional hour. The solvent was removed in vacuo and water $\left(30 \mathrm{~cm}^{3}\right)$ added. This mixture was extracted with DCM (3 x $\left.60 \mathrm{~cm}^{3}\right)$ and the combined organic layers washed with water $\left(60 \mathrm{~cm}^{3}\right)$, dried and evaporated in vacuo to give a dark brown oil. Flash column chromatography (silica, hexane $\rightarrow 25 \%$ ether/hexane) followed by crystallisation gave (Z,E)-2-formyl-3-(4perfluorophenyl-1-methyl-2-phenylbuta-1,3-dienyl)thiophene (0.583 g, 58\%) as pale yellow crystals, mp $127-129{ }^{\circ} \mathrm{C}$ (hexane), (Found $\mathrm{M}^{+}$, 420.0601. $\mathrm{C}_{22} \mathrm{H}_{13} \mathrm{~F}_{5} \mathrm{OS}$ requires $\mathrm{M}^{+}$, 420.0607); $\delta_{\mathrm{H}} 2.46$ (3 H, s, $\underline{\mathrm{CH}}_{3}$ ), 6.19 (1 H, d, C$\left(\right.$ olefinic), J 16.3), 6.90 (1 H, d, $\underline{\mathrm{H}}_{4}, J$ 5.0), 6.91-7.27 (5 H,

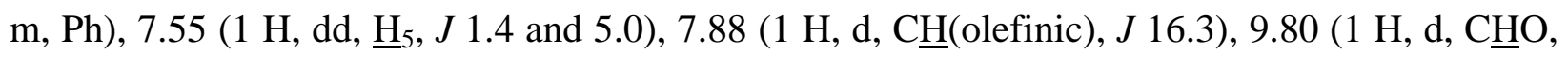
$J$ 1.3); $\delta_{\mathrm{C}} 21.9\left(\underline{\mathrm{CH}}_{3}\right), 118.3,127.8,128.7,130.5,130.7,134.4,135.4$ (ㄷH olefinic and aromatic), 133.6, 135.4, 137.6, 138.1, 141.3, 153.4 (quaternary olefinic and aromatic), 183.3 (ㄷO) (all quaternary $\underline{\mathrm{C}}-\mathrm{F}$ carbons were unobserved).

(Z,E)-2-Formyl-3-(4-perfluorophenyl-1-methyl-2-phenylbuta-1,3-dienyl)thiophene-p-tosylhydrazone (20b, Ar $\left.=\mathbf{C}_{6} \mathbf{F}_{5}\right)$. A solution of $p$-tosylhydrazide $(0.25 \mathrm{~g}, 1.6 \mathrm{mmol})$ in ethanol $\left(10 \mathrm{~cm}^{3}\right)$ was added to a solution of $(Z, E)-2-$ formyl-3-(4-perfluorophenyl-1-methyl-2phenylbuta-1,3-dienyl)thiophene $19 b(0.50 \mathrm{~g}, 1.2 \mathrm{mmol})$ in ethanol $\left(10 \mathrm{~cm}^{3}\right)$. The reaction mixture was heated at $40{ }^{\circ} \mathrm{C}$ for $1 \mathrm{~h}$, cooled to room temperature and stirred overnight. The solvent was removed in vacuo to give a pale yellow solid. Crystallisation gave (Z,E)-2-formyl-3(4-perfluorophenyl-1-methyl-2-phenylbuta-1,3-dienyl)thiophene $\quad$-tosylhydrazone $(0.630 \mathrm{~g}$, $89 \%$ ) as very pale yellow crystals, mp $175^{\circ} \mathrm{C}$ (with decomp.) (hexane-ethanol), (Found (M+1) ${ }^{+}$, 589.1048. $\mathrm{C}_{29} \mathrm{H}_{21} \mathrm{~F}_{5} \mathrm{~N}_{2} \mathrm{O}_{2} \mathrm{~S}_{2}$ requires $(\mathrm{M}+1)^{+}$, 589.1042); $\delta_{\mathrm{H}}\left(\left[\mathrm{D}_{6}\right]-\mathrm{DMSO}\right) 2.24\left(3 \mathrm{H}, \mathrm{s}, \mathrm{C}_{3}\right)$,

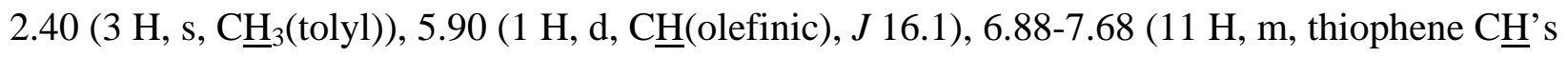

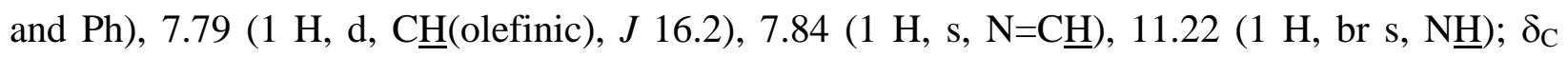
([D $]$-DMSO) 21.6, $21.8\left(\underline{\mathrm{CH}}_{3}\right), 116.4,127.7,127.9,128.6,130.0,130.5,130.8,136.6,142.0$ (ㅌH olefinic and aromatic), 113.0, 132.6, 136.9, 138.6, 139.7, 142.9, 144.2, 146.6 (quaternary olefinic, aromatic and $\underline{\mathrm{C}}$-F) (all other quaternary $\underline{\mathrm{C}}-\mathrm{F}$ carbons were unobserved; $\delta_{\mathrm{F}}(235.4 \mathrm{MHz})$ 
([D $]$-DMSO) -16.3 (1F, t, p-CF, $J$ 22.2), -22.7 (2F, td, $m$-CF, $J 7.3$ and 23.2), -154.8 (2F, dd, $o-$ CE, $J 7.3$ and 23.4).

Generation and reactions of 2-diazomethyl-3-(1,3-dienyl)thiophenes 12a,b and 13a,b. These intermediates were generated, as in previous work ${ }^{2}$, by the thermal decomposition of the sodium salts of the corresponding $p$-tosylhydrazones under aprotic conditions in DME as solvent. All reactions were carried out under nitrogen and in the dark.

(E,E)-2-Diazomethyl-3-(1-methyl-2,4-diphenylbuta-1,3-dienyl)thiophene (12a). (i) At $80{ }^{\circ} \mathrm{C}$. A methanolic solution of sodium methoxide $\left(1 \mathrm{~cm}^{3}, 0.570 \mathrm{M}, 0.570 \mathrm{mmol}\right)$ was added to a solution of ( $E, E)$-2-formyl-3-(1-methyl-2,4-diphenylbuta-1,3-dienyl)thiophene $p$-tosylhydrazone (0.303 g, $0.610 \mathrm{mmol})$ in anhydrous methanol $\left(5 \mathrm{~cm}^{3}\right)$. The reaction mixture was stirred for $1 \mathrm{~h}$ at room temperature, then the solvent was removed in vacuo at room temperature to leave the sodium salt. The latter was dried in the evaporation flask at room temperature under high vacuum over phosphorus pentoxide in a desiccator for $12 \mathrm{~h}$. Dry DME $\left(20 \mathrm{~cm}^{3}\right)$ was added to the flask and the mixture heated at reflux for $3 \mathrm{~h}$. After cooling to room temperature the reaction mixture was filtered through a pad of Celite and the solvent removed in vacuo to give a yellow oil which was shown by TLC to have two components (50\% ether/hexane). Dry-column flash chromatography (silica, hexane $\rightarrow 50 \%$ ether/hexane) gave (a) 3-methyl-1,2-diphenyl-1a,6bdihydro-1H-6-thiacyclopropa[e]indene $22(0.107 \mathrm{~g}, 56 \%)$ as a pale yellow solid, mp $124-126{ }^{\circ} \mathrm{C}$ (pentane), (Found $\mathrm{M}^{+}$, 314.1135. $\mathrm{C}_{22} \mathrm{H}_{18} \mathrm{~S}$ requires $\mathrm{M}^{+}$, 314.1129); $\delta_{\mathrm{H}} 1.44$ (1 H, br t, $\mathrm{C} \underline{H}, J$ 4.3), 2.07 (3 H, d, $\underline{\mathrm{H}}_{3}, J$ 0.27), 2.49 (1 H, dd, $\underline{\mathrm{H}}, J 4.5$ and 8.5), 2.92 (1 H, dd, $\underline{\mathrm{H}}, J 4.2$ and 8.6), 6.97-7.30 (12 H, m, thiophene $\mathrm{C} \underline{\mathrm{H}}$ 's and $\mathrm{Ph}) ; \delta_{\mathrm{C}} 18.7\left(\underline{\mathrm{CH}}_{3}\right), 25.9,29.9,31.2,122.1,125.2$, 125.6, 126.0, 127.2, 128.4, 128.9, 129.7 (ㄷH saturated and aromatic), 133.4, 133.5, 137.0, 143.5, 148.8 (quaternary olefinic and aromatic), and (b) 7-methyl-8,12-diphenyl-3-thia-10,11diazatricyclo[7,2,1,0 $0^{2,6}$ ]dodeca-2(6),4,7,10-tetraene 21a $(0.080 \mathrm{~g}, 38 \%)$ as a yellow oil. (Found $(\mathrm{M}+1)^{+}, 343.1261 . \mathrm{C}_{22} \mathrm{H}_{18} \mathrm{~N}_{2} \mathrm{~S}$ requires $(\mathrm{M}+1)^{+}$, 343.1269); $\delta_{\mathrm{H}} 1.96\left(3 \mathrm{H}, \mathrm{s}, \mathrm{C}_{3}\right), 3.56(1 \mathrm{H}, \mathrm{s}$,

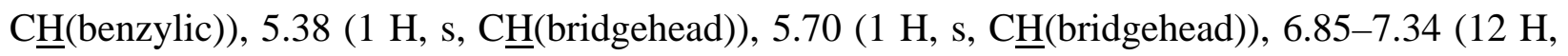
$\mathrm{m}$, thiophene $\mathrm{C} \underline{\mathrm{H}}$ 's and $\mathrm{Ph}) ; \delta_{\mathrm{C}} 23.1\left(\underline{\mathrm{CH}}_{3}\right), 42.1,88.1,97.4,123.8,126.8,127.4,127.6,129.1$, 129.4, 130.8 (ㄷH saturated and aromatic), 130.4, 135.8, 137.2, 137.6, 141.8, 145.2 (quaternary olefinic and aromatic).

(ii) At reduced temperature. The sodium salt from the $p$-tosylhydrazone $(0.25 \mathrm{~g}, 0.480 \mathrm{mmol})$ was prepared and dried as above. Its solution in DME $\left(20 \mathrm{~cm}^{3}\right)$ was stirred at room temperature for 2 days then heated at $50{ }^{\circ} \mathrm{C}$ for $4 \mathrm{~h}$. Dry-column flash chromatography (silica, hexane $\rightarrow$ $50 \%$ ether/hexane) gave 7-methyl-8,12-diphenyl-3-thia-10,11-diazatricyclo[7,2,1,02,6 $]$ dodeca2(6),4,7,10-tetraene 21a $(0.120,70 \%)$ as a yellow solid which could not be crystallised, mp 119$121{ }^{\circ} \mathrm{C}$; (Found $(\mathrm{M}+1)^{+}, 343.1270 . \mathrm{C}_{22} \mathrm{H}_{18} \mathrm{~N}_{2} \mathrm{~S}$ requires $\left.(\mathrm{M}+1)^{+}, 343.1269\right) . \delta_{\mathrm{H}} 1.96(3 \mathrm{H}, \mathrm{s}$,

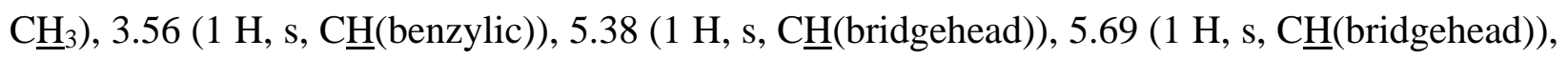
6.85-7.34 (12 H, m, thiophene $\underline{\mathrm{CH}}^{\prime} \mathrm{s}$ and $\left.\mathrm{Ph}\right) ; \delta_{\mathrm{C}} 23.1\left(\underline{\mathrm{CH}}_{3}\right), 42.1,88.1,97.4,123.8,126.8$, 127.5, 127.6, 129.1, 129.4, 130.8 (ㄷH saturated and aromatic), 130.1, 135.8, 137.2, 137.6, 141.8, 145.0 (quaternary olefinic and aromatic). 


\section{(E,E)-2-Diazomethyl-3-(4-perfluorophenyl-1-methyl-2-phenylbuta-1,3-dienyl)thiophene}

(12b). A methanolic solution of sodium methoxide $\left(1 \mathrm{~cm}^{3}, 0.400 \mathrm{M}, 0.400 \mathrm{mmol}\right)$ was added to a solution of ( $E, E)$-2-formyl-3-(4-perfluorophenyl-1-methyl-2-phenylbuta-1,3-dienyl)thiophene $p$ tosylhydrazone $(0.254 \mathrm{~g}, 0.420 \mathrm{mmol})$ in anhydrous methanol $\left(5 \mathrm{~cm}^{3}\right)$. The reaction mixture was stirred for $1 \mathrm{~h}$ at room temperature, then the solvent was removed in vacuo at room temperature to leave the sodium salt. The latter was dried in the evaporation flask at room temperature under high vacuum over phosphorus pentoxide in a desiccator for $12 \mathrm{~h}$. Dry DME $\left(20 \mathrm{~cm}^{3}\right)$ was added to the flask and the mixture stirred at room temperature for 3 days then heated at $50{ }^{\circ} \mathrm{C}$ for $6 \mathrm{~h}$. After cooling to room temperature the reaction mixture was filtered through a pad of Celite and the solvent removed in vacuo to give a yellow oil which was shown by TLC to have two components (50\% ether/hexane). Dry-column flash chromatography (silica, hexane $\rightarrow 50 \%$ ether/hexane) gave (a) non-polar material probably due to decomposition/polymerisation and (b) 12-perfluorophenyl-7-methyl-8-phenyl-3-thia-10,11-diazatricyclo[7,2,1,0 2,6]dodeca-2(6),4,7,10tetraene 21b $(0.114 \mathrm{~g}, 63 \%)$ as a pale yellow oil, (Found $(\mathrm{M}+1)^{+}$, 433.0793. $\mathrm{C}_{22} \mathrm{H}_{13} \mathrm{~F}_{5} \mathrm{~N}_{2} \mathrm{~S}$ requires $(\mathrm{M}+1)^{+}$, 433.0797); $\delta_{\mathrm{H}} 2.00\left(3 \mathrm{H}, \mathrm{s}, \mathrm{C}_{3}\right), 4.00(1 \mathrm{H}, \mathrm{s}, \mathrm{C} \underline{\mathrm{H}}$ (benzylic)), $5.34(1 \mathrm{H}, \mathrm{s}$, C $\underline{H}$ (bridgehead)), 5.85 (1 H, s, C (bridgehead)), 7.25-7.38 (7 H, m, thiophene CH's and Ph); $\delta_{\mathrm{C}}$ $23.1\left(\mathrm{CH}_{3}\right), 33.1,85.7,95.8,124.2,127.7,128.9,129.2,130.9$ ( $\underline{\mathrm{CH}}$ saturated and aromatic), 130.1, 130.5, 134.7, 136.6, 137.1, 144.5 (quaternary olefinic and aromatic), (all quaternary $\underline{\mathrm{C}}$-F carbons were unobserved).

(Z,Z)- and (Z,E)-2-Diazomethyl-3-(1-methyl-2,4-diphenylbuta-1,3-dienyl) thiophene (13a). (i) At $80{ }^{\circ} \mathrm{C}$. A methanolic solution of sodium methoxide $\left(1 \mathrm{~cm}^{3}, 0.572 \mathrm{M}, 0.572 \mathrm{mmol}\right)$ was added to a solution of (Z,Z)- and (Z,E)-2-formyl-3-(1-methyl-2,4-diphenylbuta-1,3dienyl)thiophene $p$-tosylhydrazone $(0.30 \mathrm{~g}, 0.602 \mathrm{mmol})$ in anhydrous methanol $\left(5 \mathrm{~cm}^{3}\right)$. The reaction mixture was stirred for $1 \mathrm{~h}$ at room temperature, then the solvent was removed in vacuo at room temperature to leave the sodium salt. The latter was dried in the evaporation flask at room temperature under high vacuum over phosphorus pentoxide in a desiccator for $12 \mathrm{~h}$. Dry DME $\left(20 \mathrm{~cm}^{3}\right)$ was added to the flask and the mixture heated at reflux for $3 \mathrm{~h}$. After cooling to room temperature the reaction mixture was filtered through a pad of Celite and the solvent removed in vacuo to leave an amorphous orange solid which was shown by TLC to have two components (50\% ether/hexane). Dry-column flash chromatography (silica, hexane $\rightarrow 30 \%$ ether/hexane) gave (a) the carbene "dimer" 25 (0.205 g, 54\%) which rapidly decomposed/polymerised, $\mathrm{m} / \mathrm{z} 629(\mathrm{M}+1)^{+}$; and (b) 2-formyl-3-(1-methyl-2,4-diphenylbuta-1,3dienyl)thiophene azine 24 as an 2:1 mixture of $(Z, Z)$ and $(Z, E)$ isomers $(0.080 \mathrm{~g}, 40 \%)$ as a solid which could not be crystallised., (Found $(\mathrm{M}+1)^{+}$, 657.2391. $\mathrm{C}_{44} \mathrm{H}_{36} \mathrm{~N}_{2} \mathrm{~S}_{2}$ requires $(\mathrm{M}+1)^{+}$, 657.2398); $\delta_{\mathrm{H}} 1.88 *\left(\mathrm{~d}, \mathrm{C}_{3}, J\right.$ 1.3), 6.34* (dq, $\underline{\mathrm{C}}$ (olefinic), $J 12.1$ and 1.3), 6.60* (br d, $\mathrm{C} \underline{\mathrm{H}}$ (olefinic), $J$ 11.0), 8.56* (1 H, d, N=C,$J$ 0.8), 2.29 (s, $\underline{\mathrm{C}}_{3}$ ), 6.15 (d, $\underline{\mathrm{CH}}($ olefinic), $J$ 16.0), 6.94-7.36 (26 H, m, thiophene $\mathrm{C} \underline{H}$ 's, $\mathrm{Ph}$ and $\mathrm{C} \underline{\mathrm{H}}$ (olefinic)); $\delta_{\mathrm{C}} 21.8,23.9\left(\mathrm{C}_{3}\right), 127.0,127.8$, 128.1, 128.5, 128.8, 129.0, 129.2, 129.8, 130.0, 130.5, 132.2 ( $\mathrm{CH}$ olefinic and aromatic), 137.9, 138.1, 140.1, 150.0, 155.4 (quaternary olefinic and aromatic) (* indicates the major isomer). 
(ii) At room temperature. The sodium salt from the $p$-tosylhydrazone $(0.20 \mathrm{~g}, 0.400 \mathrm{mmol})$ was prepared and dried as above. Its solution in DME $\left(50 \mathrm{~cm}^{3}\right)$ was stirred at room temperature for 7 days. The reaction mixture was shown by TLC to have four components (50\% ether/hexane). Dry-column flash chromatography (silica, hexane $\rightarrow 50 \%$ ether/hexane) gave no identifiable products.

2-Formyl-3-(1-methyl-2,4-diphenylbuta-1,3-dienyl)thiophene azine as a 2:1 mixture of (Z,Z) and (Z,E) isomers (24). (Z,Z)- and (Z,E)-2-Formyl-3-(1-methyl-2,4-diphenylbuta-1,3dienyl)thiophene $(0.202 \mathrm{~g}, 0.61 \mathrm{mmol})$ was dissolved in ethanol $\left(3 \mathrm{~cm}^{3}\right)$ and heated to $50{ }^{\circ} \mathrm{C}$. Hydrazine hydrate $(15 \mathrm{mg}, 0.30 \mathrm{mmol}$ ) was added followed by one drop of conc. hydrochloric acid. A yellow solid was deposited, which was identified as the intermediate hydrazone. The reaction mixture was heated at reflux for $3 \mathrm{~h}$, a further portion of aldehyde was added (95 mg, $0.300 \mathrm{mmol}$ ) followed by another drop of conc. hydrochloric acid and heated at reflux for a further $1.5 \mathrm{~h}$. The solvent was removed in vacuo to leave a yellow solid that could not be crystallised. Short path column chromatography (silica, 75\% ether/hexane) gave an 2:1 mixture of $(Z, Z)$ and $(Z, E)-2$-formyl-3-(1-methyl-2,4-diphenylbuta-1,3-dienyl)thiophene azine (0.186 g, $47 \%)$ as a yellow oil identical with that isolated from the reaction of $13 a$.

(Z,E)-2-Diazomethyl-3-(4-perfluorophenyl-1-methyl-2-phenylbuta-1,3-dienyl)thiophene (13b). A methanolic solution of sodium methoxide $\left(1 \mathrm{~cm}^{3}, 0.480 \mathrm{M}, 0.480 \mathrm{mmol}\right)$ was added to a solution of (Z,E)-2-formyl-3-(4-perfluorophenyl-1-methyl-2-phenylbuta-1,3-dienyl)thiophene $p$ tosylhydrazone $(0.300 \mathrm{~g}, 0.510 \mathrm{mmol})$ in anhydrous methanol $\left(5 \mathrm{~cm}^{3}\right)$. The reaction mixture was stirred for $1 \mathrm{~h}$ at room temperature, then the solvent was removed in vacuo at room temperature to leave the sodium salt. The latter was dried in the evaporation flask at room temperature under high vacuum over phosphorus pentoxide in a desiccator for $12 \mathrm{~h}$. Dry DME $\left(20 \mathrm{~cm}^{3}\right)$ was added to the flask and the mixture heated at reflux for $3 \mathrm{~h}$. After cooling to room temperature the reaction mixture was filtered through a pad of Celite and the solvent removed in vacuo to give a yellow oil. Dry-column flash chromatography (silica, hexane $\rightarrow 50 \%$ ether/hexane) gave several components, none of which showed, in their ${ }^{1} \mathrm{H}$ NMR spectra, any indication of the presence of the thiadiazatricyclododecatetraene, thiacyclopropaindene or phthalazine 21b, 22b, $\mathbf{1 4 b}(\mathbf{A r}=$ $\mathbf{C}_{6} \mathbf{F}_{5}$ ) respectively.

\section{References and Notes}

1. Undergraduate Research Project 2001-02.

2. Sharp, J. T.; Wilson, P.; Parsons, S.; Gould, R. O. J. Chem. Soc., Perkin Trans. 1 2000, 1139.

3. Cessford A. G. Ph.D. Thesis, University of Edinburgh, 2002.

4. (a) Padwa, A.; Ku, H. Tetrahedron Lett. 1980, 21, 1009. (b) Padwa, A.; Rodriguez, A. Tetrahedron Lett. 1981, 22, 187. (c) Miyashi, T.; Fujii, Y.; Nishizawa, Y.; Mukai, T. J. Am. Chem. Soc. 1981, 103, 725. 
5. (a) Arnold, Z.; Holy, A. Collect. Czech. Chem. Commun. 1961, 26, 3059. (b) Robertson, I. R.; Sharp, J. T. Tetrahedron 1984, 40, 3095.

6. Practical Organic Chemistry, a Student Handbook of Techniques, Sharp, J. T.; Gosney, I; Rowley, A. G., Chapman and Hall: London, 1989; p 160 and 163.

7. Hermant, R. M.; Bakker, N. A. C.; Scherer, T.; Kijnen, B.; Verhoeven, J. W. J. Am. Chem. Soc. 1990, 112, 1214. 